This item was submitted to Loughborough's Research Repository by the author.

Items in Figshare are protected by copyright, with all rights reserved, unless otherwise indicated.

\title{
Considerations that affect optimised simulation in a running jump for height
}

PLEASE CITE THE PUBLISHED VERSION

PUBLISHER

(C) Elsevier

VERSION

AM (Accepted Manuscript)

LICENCE

CC BY-NC-ND 4.0

REPOSITORY RECORD

Wilson, Cassie, Maurice R. Yeadon, and Mark A. King. 2019. "Considerations That Affect Optimised Simulation in a Running Jump for Height”. figshare. https://hdl.handle.net/2134/6187. 
This item was submitted to Loughborough's Institutional Repository (https://dspace.lboro.ac.uk/) by the author and is made available under the following Creative Commons Licence conditions.

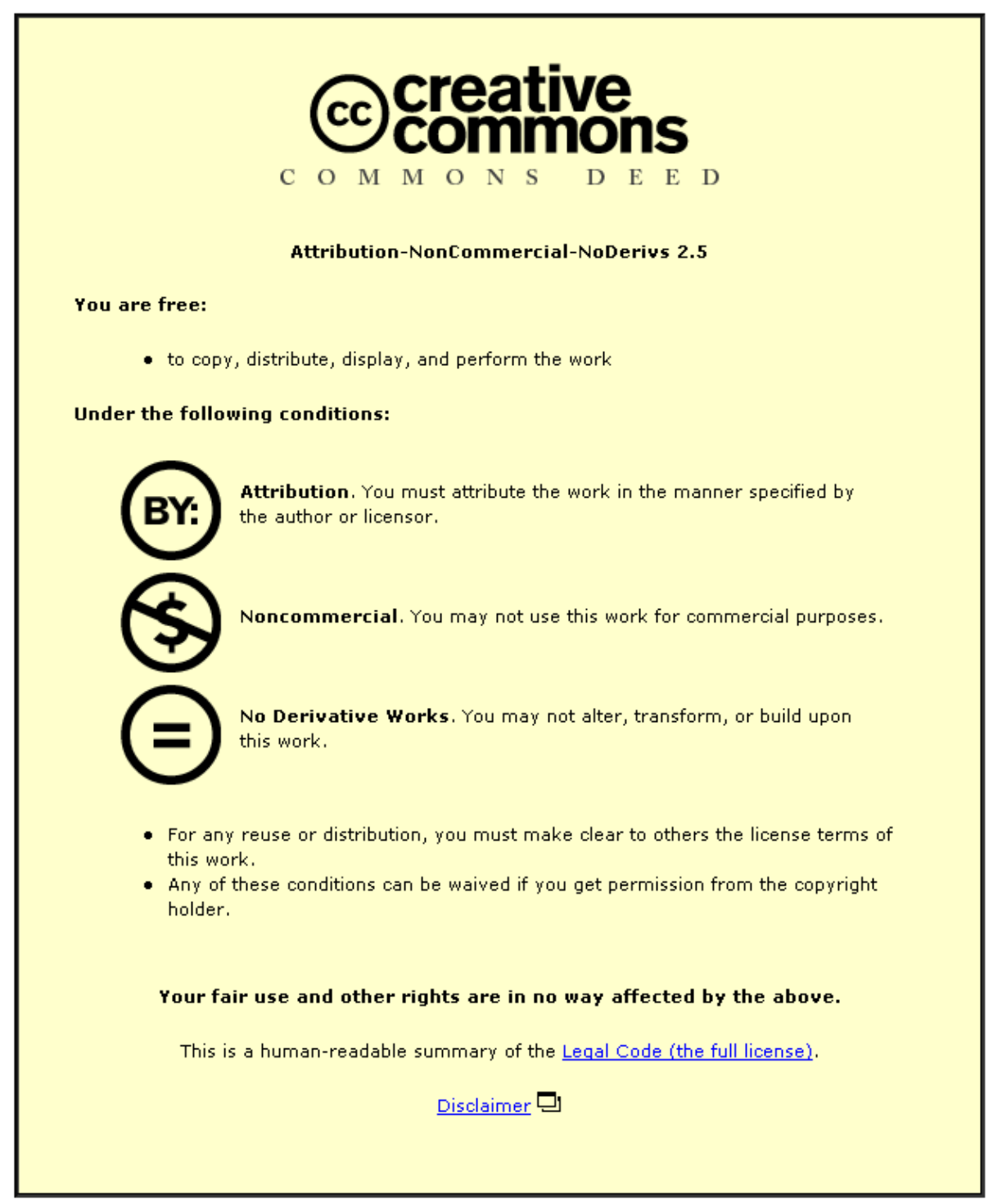

For the full text of this licence, please go to: http://creativecommons.org/licenses/by-nc-nd/2.5/ 


\title{
Considerations that affect optimised simulation in a running jump for height
}

\author{
Cassie Wilson $^{1}$, Maurice R. Yeadon ${ }^{2}$ and Mark A. King ${ }^{2}$ \\ ${ }^{1}$ Cardiff School of Sport, University of Wales Institute Cardiff, Cardiff, CF23 6XD, UK. \\ ${ }^{2}$ School of Sport and Exercise Sciences, Loughborough University, Loughborough LE11 3TU, UK.
}

\begin{abstract}
This study used a computer simulation model to investigate various considerations that affect optimum peak height in a running jump. A planar eight-segment computer simulation model with extensor and flexor torque generators at five joints, was formulated and customised to an elite male high jumper. A simulation was matched to a recorded high jumping performance by varying the activation profiles of each of the torque generators giving a simulated peak height of $1.99 \mathrm{~m}$ compared to the recorded performance of $2.01 \mathrm{~m}$. In order to maximise the peak height reached by the mass centre in the flight phase the activation profiles were varied, keeping the same initial conditions as in the matching simulation. Optimisations were carried out without any constraints, with constraints on the angular momentum at takeoff, with further constraints on joint angles, and with additional requirements of robustness to perturbations of activation timings. A peak height of $2.37 \mathrm{~m}$ was achieved in the optimisation without constraints. Introducing the three constraints in turn resulted in peak heights of $2.21 \mathrm{~m}, 2.14 \mathrm{~m}$ and $1.99 \mathrm{~m}$. With all three types of constraint included the peak height was similar to that achieved in the recorded performance. It is concluded that such considerations have a substantial influence on optimum technique and must be included in studies using optimised simulations.
\end{abstract}

Keywords : computer simulation, optimisation, constraints, robustness

\section{Introduction}

Research on high jumping performance has included both experimental studies (Brüggemann and Loch, 1992; Dapena and Chung, 1988; Dapena et al., 1990; Greig and Yeadon, 2000) and theoretical studies (Alexander, 1990; Hubbard and Trinkle, 1985). While optimal approach characteristics in high jumping have been investigated by Alexander (1990) and Greig and Yeadon (2000), investigations into optimal muscle activation timings are limited. Optimal activation timing in simulations of squat jumping has been investigated by Pandy et al. (1990) and van Soest et al. (1994) who found that the heights reached by the models were broadly comparable with actual performances. However, simply maximising the peak jump height of the mass centre may result in a theoretical simulation that is inaccurate since various factors will have been neglected.

One factor to be considered in the optimisation of jump height is the technical requirements of the skill. For example, in a high jumping performance the appropriate angular momentum at takeoff is crucial if the athlete is to complete the necessary rotation in the air for a successful performance (Dapena, 1988). A second factor is the anatomical range of movement at each joint since a simulation that violates joint constraints may give an unrealistic jump height (Umberger, 2005). A further factor for success in competitive elite sport is consistency of performance. In order for an athlete to be consistent, performance should be robust to small changes in activation timing. In targeted movements Harris and Wolpert (1998) demonstrated 
that the time profile of the neural input could be explained by the minimisation of endpoint error. Similarly in order to obtain consistent performance in high jumping, the activation time histories may be optimised so as to give only small changes in performance when the activation timings are perturbed. While the effect of each of these factors has been investigated in differing activities no study has incorporated all three factors to determine their relative effects in a single activity.

The purpose of this study was to investigate optimised simulated performance in a running jump for height taking into consideration the appropriate angular momentum, the anatomical ranges of movement and the requirement of robustness of performance.

\section{Methods}

A planar torque-driven computer simulation model of the contact phase in a running jump for height was developed and was used subsequently to investigate the effect of imposing angular momentum, anatomical and robustness requirements on maximum jump height.

An international male high jumper of height $1.89 \mathrm{~m}$ and mass $82 \mathrm{~kg}$, with a personal competition best of $2.31 \mathrm{~m}$ participated in the study. The athlete gave informed consent for the procedures, which were carried out in accordance with the protocol approved by Loughborough University Ethical Advisory Committee. Ninety-five anthropometric measurements were taken on the athlete and segmental inertia parameters were calculated using the geometric inertia model of Yeadon (1990b). The approach, takeoff and flight phases of a high jumping trial were recorded at an athletics track using two video cameras. 15 body landmarks were reconstructed using the Direct Linear Transformation (Karara, 1980) with camera synchronisation effected using the digitised landmark data (Yeadon and King, 1999). The coordinate data and the inertia data were used to calculate the jumper's orientation and configuration angles throughout the movement, along with the mass centre velocity and whole-body angular momentum about the mass centre (Yeadon, 1990a, 1990c). The component of angular momentum about an axis perpendicular to the vertical plane through the mass centre velocity at takeoff (close to the sagittal plane at touchdown) was calculated for subsequent use with the planar model of the takeoff. The time histories of the orientation and configuration angles were fitted using quintic splines (Wood and Jennings, 1979) in order to obtain angle and angular velocity estimates throughout the movement. Although the recorded high jumping performance was three-dimensional in many respects, the contact phase was essentially planar since the mean deviation from the vertical plane through the mass centre path was less than $5^{\circ}$. 


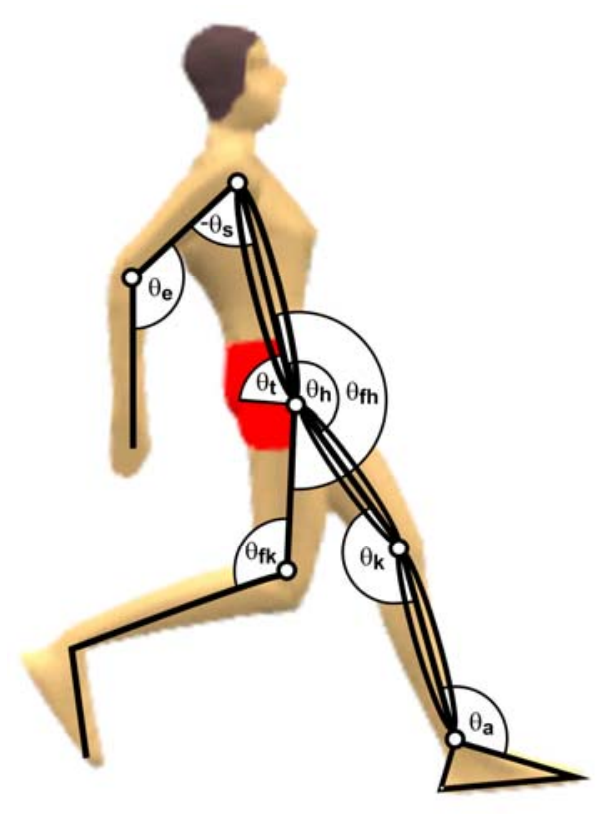

Figure 1. Angle definitions for the eight-segment model.

A planar forward dynamics computer simulation model of the contact phase in running jumps for height was developed and customised to the athlete using subjectspecific inertia, strength and visco-elastic parameters (King et al., 2006). The model comprised eight segments representing foot, calf and thigh of the takeoff leg; shank and thigh of the free leg; trunk + head; upper arm and lower arm (Figure 1). Torque generators consisting of rotational elastic and contractile elements in series acted around five joints (ankle, knee and hip of the takeoff leg; hip of the free leg and shoulder) with extensors and flexors represented separately. The torque produced during a simulation was given by the product of the activation and the maximum voluntary joint torque function whose parameters were determined from dynamometer measurements (King et al., 2006; Yeadon et al., 2006). Passive torque generators which prevent joints from exceeding their anatomical limits were not included in the model. The activation of each torque generator ranged from 0 to 1 during a simulation and was specified by a time profile. Two different profiles were used to represent the activation time histories of the agonist (ankle, knee and hip extensor; shoulder and free hip flexor) and antagonist (ankle, knee and hip flexor; shoulder and free hip extensor) muscle groups. For the agonists the activation was allowed to rise as a quintic function of time from an initial level $a_{i}$ to an upper level $a_{u}$ over a time period $t_{r}$ and then at time $t_{\text {off }}$ fall to zero on a quintic over a time period $t_{d}$, whereas for the antagonists the activation was allowed to fall to zero from an initial level $a_{i}$ over a time period $t_{d}$ and then at time $t_{o n}$ rise to full activation over a time period $t_{r}$. It was thought that these profiles were sufficiently complex in that they allowed cocontraction which could produce fast ramp times for the net joint torque but were not over-complex for the short takeoff duration. 

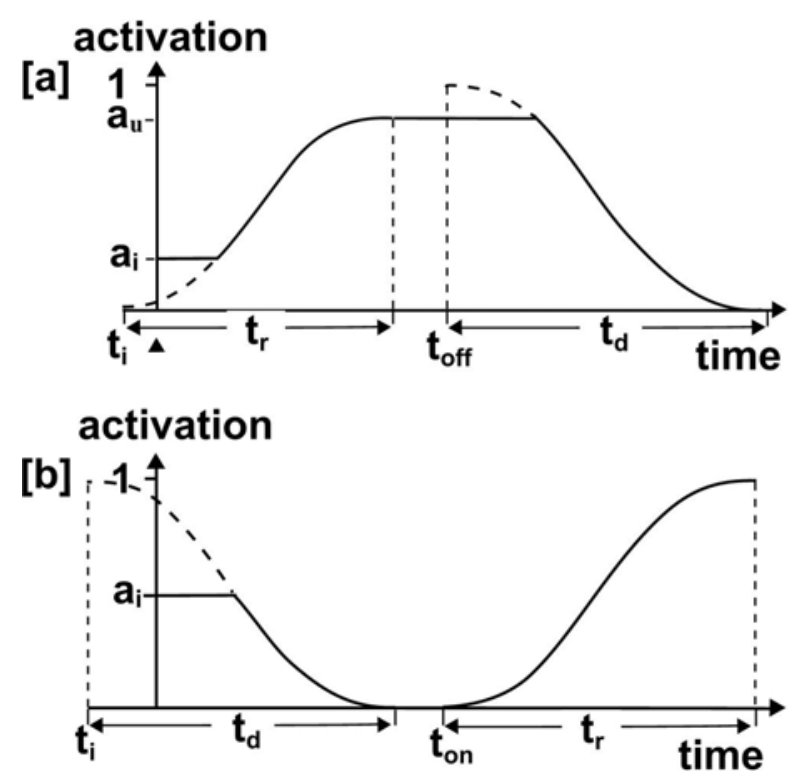

Figure 2. (a) Six-parameter activation profile for the agonist torque generators in which the activation rises as quintic function of time from an initial level to an upper level and then falls to zero on another quintic function. (b) Similar five-parameter activation profile for the antagonist torque generators in which the activation falls to zero from an initial level and then rises to full activation.

Six parameters were needed to specify the activation time histories of each agonist torque generator and five were needed for each antagonist torque generator, resulting in a total of 11 activation parameters per joint (King et al., 2006). The remaining two joints in the model (elbow and free knee) were angle-driven using the splined joint angle time histories of the recorded jump since movement at these two joints was expected to make only a small contribution to jump height. Wobbling masses represented as moveable rigid bodies connected to fixed rigid bodies by nonlinear spring-damper systems were included in the shank and thigh segments of the takeoff leg and in the trunk segment. The foot-ground interface was modelled as a spring-damper system with vertical and horizontal non-linear stiffness and damping components situated at the toe and the heel.

Visco-elastic parameter values for the wobbling masses and initial estimates of the visco-elastic parameter values for the foot-ground interface of the torque-driven model were obtained using an angle-driven version of the model (Wilson et al., 2006). Input to the torque-driven model consisted of the kinematics at touchdown, the activation time histories of the 10 torque generators, and the time histories of the elbow and free knee angles. Model output comprised the time histories of the footground spring-damper displacements, joint angles and trunk orientation from which mass centre position and velocity together with angular momentum about the mass centre were calculated.

A simulation which matched the recorded performance during takeoff was found by varying the 55 torque generator activation parameters and three stiffness parameters (one horizontal and two vertical) of the foot-ground interface to minimise the sum of a difference score and various penalties using the Simulated Annealing algorithm (Corana et al., 1987). The three stiffness parameters were allowed to vary by $\pm 50 \%$ from the initial estimates which were determined from performances on a laboratory floor (Wilson et al., 2006) rather than an athletics track surface. The difference score was the root mean square of five components based on the difference between simulation and performance in terms of (1) trunk orientation, (2) joint angles, 
(3) time of contact, (4) linear momentum, and (5) angular momentum similar to the procedure of King et al. (2006). Penalties were used to ensure that the matching simulation gave a peak height close to that of the performance and that joint angles remained within anatomical limits.

Four optimisations were carried out which maximised an objective function defined as the peak height reached by the mass centre during the flight phase of the simulated jump minus various constraint penalties. The peak height was calculated from mass centre height and vertical velocity at takeoff. In each optimisation the initial kinematics were set to be those used in the matching simulation (Table 1) and the 55 torque generator activation parameters were varied using Simulated Annealing to maximise the peak height reached subject to various constraints.

The first optimisation was carried out with no constraints. To determine the maximum peak height reached with a constraint on the angular momentum a second optimisation was performed with a penalty subtracted from the peak height if the angular momentum at takeoff differed from that in the recorded performance by more than $10 \%$ (an amount that could be accommodated by means of configuration changes during flight). For each $1 \%$ of angular momentum outside of the permitted range a penalty of $0.05 \mathrm{~m}$ was imposed. In the third optimisation in addition to the angular momentum penalty the knee and ankle joint angles of the takeoff leg were constrained to be less than $180^{\circ}$ and $160^{\circ}$ respectively both at takeoff and during the first $100 \mathrm{~ms}$ of the flight phase assuming constant angular acceleration using penalties of $0.01 \mathrm{~m}$ for every degree beyond each limit. This was done since these were the only joints that approached their anatomical limits in the matching simulation and then only at takeoff. The assumption of constant joint angular acceleration is a simplification and while possibly conservative it is certainly better than the usual procedure of not considering violations in the flight phase.

Once the optimum simulation with both angular momentum and anatomical constraints had been found, perturbations to joint torque generator activation timings were incorporated into the optimisation process. A sensitivity analysis was conducted and simulations were found to be most sensitive to changes in the activation timings of the knee and hip extensor torque generators. The onset timings of the torque generators of these two joints were varied by \pm 5 ms (keeping the same ramp times) producing four additional simulations ( $+5 \mathrm{~ms}$ at the knee, $-5 \mathrm{~ms}$ at the knee, $+5 \mathrm{~ms}$ at the hip, $-5 \mathrm{~ms}$ at the hip). The fourth optimisation was then run in which the score to be maximised was taken to be the average score (including constraint penalties) of the four perturbed simulations. This produced an optimised (unperturbed) simulation that was expected to be more robust to perturbations in activation timing than the third optimisation. The sensitivities of optimisations 3 and 4 to timing perturbations of \pm 5 ms were then determined using individual simulations.

Optimisation 1 was started from the matching simulation and each subsequent optimisation was started from the solution of the previous optimisation. In order to ensure that a global optimum was found by the Simulated Annealing algorithm, two additional independent optimisations were carried out for each of the four optimisations by starting from a different initial simulation and by changing the order of the optimisation parameters. Additional optimisations were started from either the matching simulation or a different optimisation solution. In each optimum solution each penalty score was zero and so the penalty weightings were suitable and did not affect the optimum. It was anticipated that a given set of activation profiles would correspond to unique time histories of net torque at each joint. If this were not the 
case then the optimisation algorithm might be expected to have difficulty in converging to a solution.

\section{Results}

The matching simulation resulted in a peak height of $1.99 \mathrm{~m}$ compared to the recorded height of $2.01 \mathrm{~m}$ with a root mean square difference score of $7.8 \%$ comprising individual scores of: $8.5^{\circ}, 13.8^{\circ}, 1.3 \%, 6.2 \%$, and $0.4 \%$ for each of the five components (trunk orientation, joint angles, time of contact, linear momentum, and angular momentum). In the matching simulation no violations of either angular momentum or anatomical constraints occurred. The horizontal stiffness parameter value at the heel and toe was $63 \%$ of the initial estimate taken from Wilson et al. (2006) while the vertical stiffness parameter values were $69 \%$ and $99 \%$ of the initial estimates at the heel and toe respectively.

Table 1. Initial conditions of the matching simulation

\begin{tabular}{|c|c|c|c|}
\hline variable & Value & variable & Value \\
\hline $\mathrm{v}_{\mathrm{cmx}}$ & $7.4 \mathrm{~ms}^{-1}$ & $\mathrm{v}_{\mathrm{cmy}}$ & $-0.58 \mathrm{~ms}^{-1}$ \\
\hline$\theta_{\mathrm{a}}$ & $85^{\circ}$ & $\dot{\theta}_{\mathrm{a}}$ & $201^{\circ} \mathrm{s}^{-1}$ \\
\hline$\theta_{\mathrm{k}}$ & $157^{\circ}$ & $\dot{\theta}_{\mathrm{k}}$ & $-58^{\circ} \mathrm{s}^{-1}$ \\
\hline$\theta_{\mathrm{h}}$ & $141^{\circ}$ & $\dot{\theta}_{\mathrm{h}}$ & $218^{\circ} \mathrm{s}^{-1}$ \\
\hline$\theta_{\mathrm{s}}$ & $-59^{\circ}$ & $\dot{\theta}_{\mathrm{S}}$ & $881^{\circ} \mathrm{s}^{-1}$ \\
\hline$\theta_{\mathrm{e}}$ & $92^{\circ}$ & $\dot{\theta}_{\mathrm{e}}$ & $-1320^{\circ} \mathrm{s}^{-1}$ \\
\hline$\theta_{\mathrm{rh}}$ & $209^{\circ}$ & $\dot{\theta}_{\mathrm{rh}}$ & $-228^{\circ} \mathrm{s}^{-1}$ \\
\hline$\theta_{\mathrm{rk}}$ & $68^{\circ}$ & $\dot{\theta}_{\mathrm{rk}}$ & $1271^{\circ} \mathrm{s}^{-1}$ \\
\hline$\theta_{\mathrm{t}}$ & $80^{\circ}$ & $\dot{\theta}_{\mathrm{t}}$ & $-46^{\circ} \mathrm{s}^{-1}$ \\
\hline
\end{tabular}

Note: See Figure 1 for angle definitions; $\mathrm{v}_{\mathrm{cmx}}$ and $\mathrm{v}_{\mathrm{cmy}}$ are the horizontal and vertical velocities of the mass centre at touchdown.

With no constraints imposed the optimised mass centre peak height was 2.37 m (optimisation 1). In this simulation, however, the angular momentum was more than twice that of the matching simulation (Table 2) resulting in an unrealistic performance in which over-rotation about the lateral axis occurred. With angular momentum constraints imposed, the optimised peak height decreased to $2.21 \mathrm{~m}$ (optimisation 2). Again, this solution was not realistic as the knee and ankle angles exceeded their anatomical limits during the flight phase (Table 2). In the third optimisation in which anatomical constraints were also imposed, the peak height was reduced further to $2.14 \mathrm{~m}$. Repeating optimisations 1-3 with different starting points or reading in the 55 torque activation parameters in a different order into the Simulated Annealing algorithm resulted in the same optimum simulations suggesting that a global rather than a local optimum had been found. The optimum activation 
onset timings at the knee and hip for optimisation 3 were perturbed by $\pm 5 \mathrm{~ms}$ producing four additional simulations. The peak heights reached by the mass centre in these simulations varied from $2.06 \mathrm{~m}$ to $2.17 \mathrm{~m}$ but all four simulations violated anatomical or angular momentum constraints (Table 3). In the fourth optimisation where the average of the four heights reached in perturbed simulations was maximised a peak height of $1.99 \mathrm{~m}$ was obtained (Table 2). When $5 \mathrm{~ms}$ timing perturbations were introduced into this optimum simulation the peak height was also $1.99 \mathrm{~m}$, with no violations of either the angular momentum or anatomical constraints (Table 3). Repeating optimisation 4 from different starting simulations and changing the order of the parameters to be varied in the Simulated Annealing algorithm resulted in optimum simulations with peak heights ranging from $1.93 \mathrm{~m}$ to $1.99 \mathrm{~m}$. In all optimisations Simulated Annealing had reduced the step length of each parameter affecting the final activation profile to a small value. This was an indication that the algorithm had converged to a solution.

Table 2. Output values of the matching simulation and the four optimisations

\begin{tabular}{|c|c|c|c|c|c|c|}
\hline & $\begin{array}{c}\text { peak } \\
\text { height } \\
{[\mathrm{m}]}\end{array}$ & $\begin{array}{c}\text { angular } \\
\text { momentum } \\
{\left[\mathrm{kg} \mathrm{m}^{2} \mathrm{~s}^{-1}\right]}\end{array}$ & $\begin{array}{c}\text { knee } \\
\text { angle } \\
\text { at TO } \\
{\left[{ }^{\circ}\right]}\end{array}$ & $\begin{array}{c}\text { knee } \\
\text { angle in } \\
\text { flight } \\
{\left[{ }^{\circ}\right]}\end{array}$ & $\begin{array}{c}\text { ankle } \\
\text { angle } \\
\text { at TO } \\
{\left[{ }^{\circ}\right]}\end{array}$ & $\begin{array}{c}\text { ankle } \\
\text { angle } \\
\text { in } \\
\text { flight } \\
{\left[{ }^{\circ}\right]}\end{array}$ \\
\hline Match & 1.99 & 23.4 & 161 & 180 & 126 & 156 \\
\hline Opt 1 & 2.37 & $55.0^{*}$ & 180 & $255^{*}$ & 145 & $246^{*}$ \\
\hline Opt 2 & 2.21 & 24.9 & 158 & $427^{*}$ & 147 & $777^{*}$ \\
\hline Opt 3 & 2.14 & 25.2 & 160 & 179 & 131 & 149 \\
\hline Opt 4 & 1.99 & 22.8 & 170 & 172 & 120 & 144 \\
\hline
\end{tabular}

Note: Opt 1 - no constraints; Opt 2 - angular momentum (AM) constraint; Opt 3 - AM and anatomical constraints; Opt 4 - as Opt 3 but with robustness requirement. * indicates a constraint violation. 
Table 3. Effect of perturbations on optimisations 3 and 4.

\begin{tabular}{|c|c|c|c|c|c|c|}
\hline $\mathrm{ms}$ & $\begin{array}{c}\text { peak } \\
\text { height } \\
{[\mathrm{m}]}\end{array}$ & $\begin{array}{c}\text { angular } \\
\text { momentum } \\
{\left[\mathrm{kgm}^{2} \mathrm{~s}^{-1}\right]}\end{array}$ & $\begin{array}{c}\text { knee } \\
\text { angle } \\
\text { at TO } \\
\left.{ }^{\circ}\right]\end{array}$ & $\begin{array}{c}\text { knee } \\
\text { angle in } \\
\text { flight } \\
\left.{ }^{\circ}\right]\end{array}$ & $\begin{array}{c}\text { ankle } \\
\text { angle } \\
\text { at TO } \\
\left.{ }^{\circ}\right]\end{array}$ & $\begin{array}{c}\text { ankle } \\
\text { angle in } \\
\text { flight } \\
{\left[^{\circ}\right]}\end{array}$ \\
\hline \multicolumn{7}{|l|}{ Opt 3} \\
\hline knee +5 & 2.16 & $30.4 *$ & 166 & 175 & 130 & 155 \\
\hline knee -5 & 2.08 & $18.1^{*}$ & 152 & $288 *$ & 134 & $298 *$ \\
\hline hip +5 & 2.17 & $32.4 *$ & 169 & 178 & 130 & 153 \\
\hline hip -5 & 2.06 & $17.3^{*}$ & 149 & $285^{*}$ & 134 & $293 *$ \\
\hline none & 2.14 & 25.2 & 160 & 179 & 131 & 149 \\
\hline \multicolumn{7}{|l|}{ Opt 4} \\
\hline knee +5 & 1.99 & 24.9 & 174 & 175 & 124 & 160 \\
\hline knee -5 & 1.99 & 20.7 & 166 & 175 & 124 & 137 \\
\hline hip +5 & 1.99 & 24.1 & 174 & 175 & 124 & 148 \\
\hline hip -5 & 1.99 & 21.0 & 164 & 167 & 123 & 139 \\
\hline none & 1.99 & 22.8 & 170 & 172 & 120 & 144 \\
\hline
\end{tabular}

Note: * indicates a constraint violation

The activation profiles used for each of the joints in optimisation 4 (robust solution) are shown in Figure 3. The agonists at the ankle, knee, hip and free hip joints all showed similar patterns of activation initially, with a fairly rapid rise from the initial level to the maximum level. The agonists and antagonists of each joint started with similar levels of activation with the exception of the hip joint of the takeoff leg where very little co-contraction occurred (Figure 3). The shoulder joint showed co-contraction throughout the movement. 

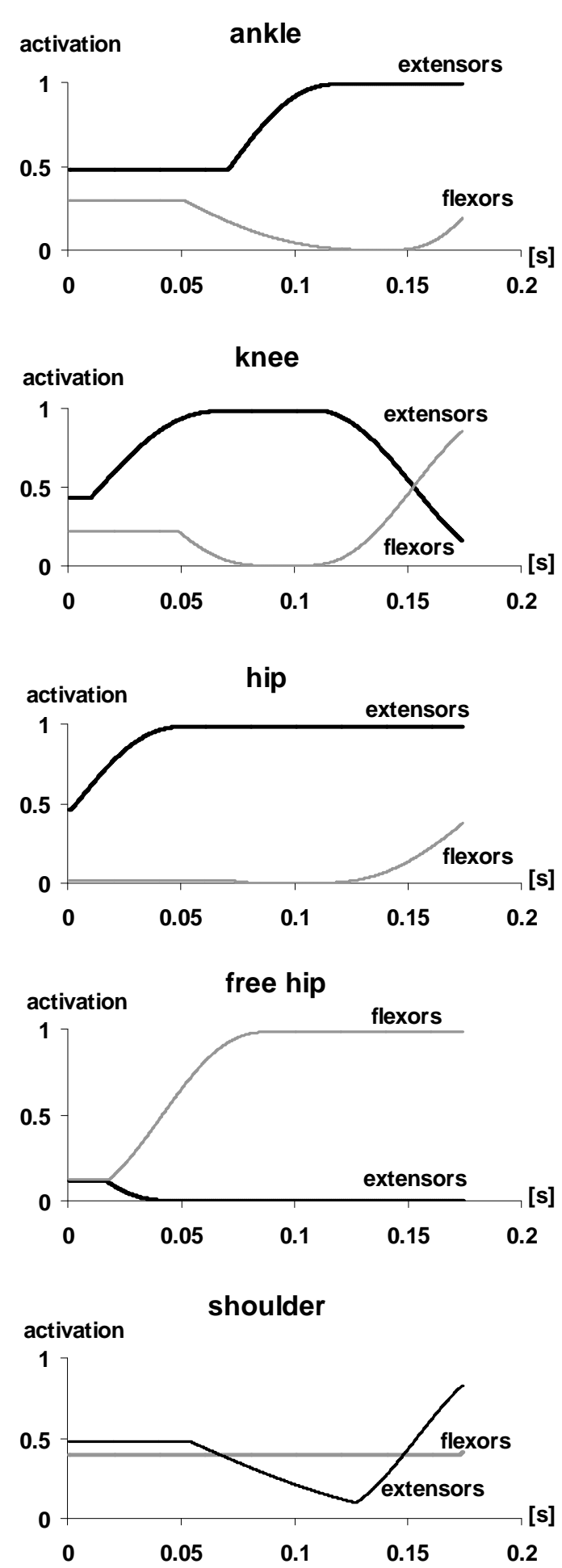

Figure 3. Activation profile of the flexors and extensors of the ankle, knee, hip, free hip and shoulder joints for the robust optimisation.

The knee activation profiles used in optimisation 1 (no constraints) and optimisation 3 (angular momentum and anatomical constraints) showed similar trends for the extensors but not for the flexors (Figure 4). In optimisation 4 the knee flexor profile was similar to that in optimisation 3 whereas the knee extensor profile showed a drop from the upper level in contrast to the profiles in optimisations 1 and 3 (Figure 4). 

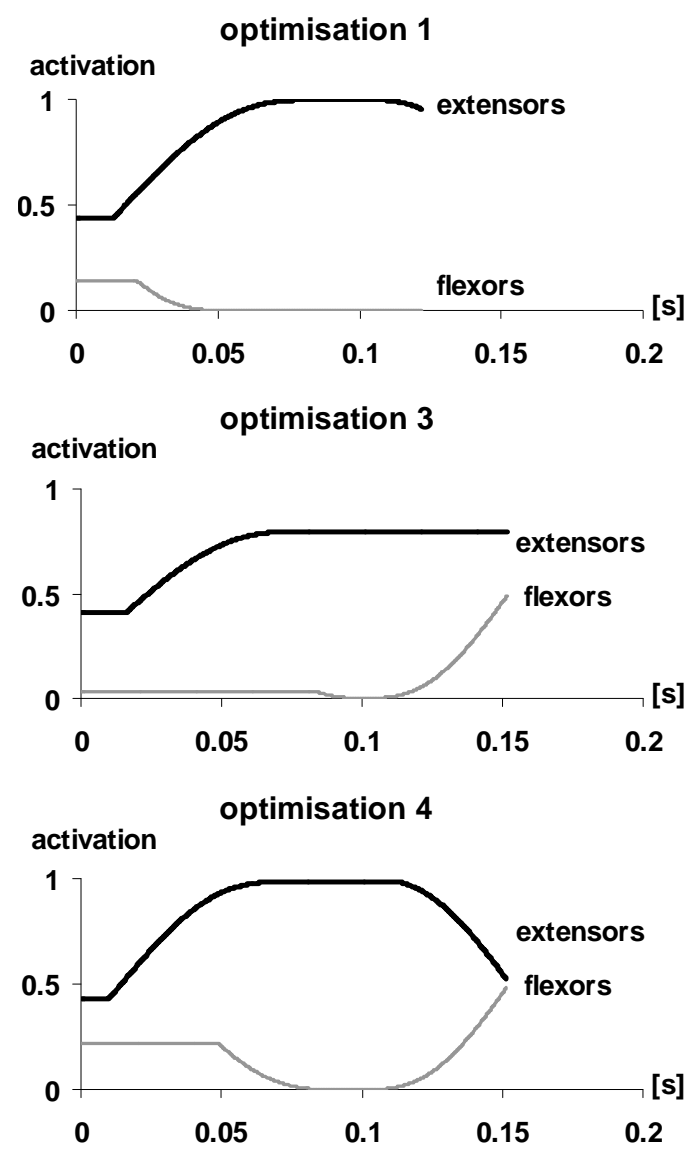

Figure 4. Activation profiles of the knee extensors and flexors for (a) optimisation 1 (no constraints), (b) optimisation 3 (angular momentum and anatomical constraints), and (c) optimisation 4 (robustness requirement).

\section{Discussion}

This paper investigated the effect of constraints on optimum performance in a running jump for height. The matching simulation inherently included the constraints of the actual (close to optimal) performance and produced a peak height of $1.99 \mathrm{~m}$ compared to the performance height of $2.01 \mathrm{~m}$. The difference of $0.02 \mathrm{~m}$ in peak height is a measure of the ability of the model to reproduce an actual performance. The optimised simulations gave peak heights varying from $2.37 \mathrm{~m}$ when there were no constraints to $1.99 \mathrm{~m}$ when angular momentum and anatomical constraints were imposed together with robustness requirements. This shows the substantial effect that such constraints have on performance. The final optimised simulation height of 1.99 $\mathrm{m}$ was close to the matching simulation height of $1.99 \mathrm{~m}$ indicating that the inclusion of the appropriate constraints in the optimisation of a sports movement will result in a simulation that is similar to an actual performance. This close correspondence also suggests that $5 \mathrm{~ms}$ is the order of magnitude of perturbation that can be accommodated by an elite high jumper and that the actual performance was close to optimal for the given touchdown conditions.

Besides the technical constraint on angular momentum a similar constraint could be imposed on the horizontal velocity at takeoff to ensure that there was a realistic amount of travel in flight. However such a constraint would not affect the final optimisation since the robust simulation produced a similar horizontal takeoff velocity to the actual performance. Similarly anatomical joint constraints could be 
required at the other joints but again these would have no effect on the final optimisation since these joints did not approach their anatomical limits in the robust simulation. An additional requirement for robustness to timing perturbations could be imposed at the ankle and this would tend to reduce the optimised height or equivalently reduce the perturbation time from $5 \mathrm{~ms}$. Such a reduction, however, may be small since the hip and knee were chosen as the most sensitive to timing perturbations. Moreover, the use of more complex activation profiles could permit larger perturbations to be accommodated. It is crucial that consideration is given to such constraints in simulation studies in order that the results are of realistic magnitude. Having identified and given consideration to constraints which should be incorporated into a simulation model of jumping, further optimisation studies such as the optimisation of initial conditions will be able to be carried out with some confidence.

Chow and Hay (2005) noted that unconstrained optimisations of long jumping lead to unrealistically large angular momentum values at takeoff. In the present study the unconstrained optimisation used twice the angular momentum component required for an actual high jump while the optimisation with the constrained angular momentum at takeoff reduced the peak height by $0.16 \mathrm{~m}$. The additional inclusion of anatomical joint constraints reduced the peak height by a further $0.07 \mathrm{~m}$ highlighting the necessity for this constraint in order to avoid hyper-extension of joints and the overestimation of performance. This is in agreement with the finding of Umberger (2005) that there was a reduction of $0.11 \mathrm{~m}$ in the height of a vertical countermovement jump when penalties were imposed to reduce protective passive joint torques during the contact phase. The final decrease of $0.15 \mathrm{~m}$ in peak height to 1.99 $m$ indicates the substantial effect of requiring consistent performance. A similar but smaller effect was obtained by Bobbert and Zandwijk (1999) who found that maximum jump heights decreased by $0.03 \mathrm{~m}$ as jumping performances were made more robust to $5 \mathrm{~ms}$ perturbations. While the effects of the three constraints have been identified in various jumping activities as noted above, each has been considered in isolation rather than cumulatively as in this study which gives an indication of their relative magnitudes.

The activation profiles of the torque generators can give a clearer insight into what is occurring in a simulation and what effect the constraints have on optimal activation technique. A sharp rise in the activation level of the knee flexors towards the end of the simulation occurred in the constrained optimisation 3 (Figure $4 \mathrm{~b}$ ) but not in the unconstrained optimisation 1 (Figure 4a). This indicates that the anatomical constraint included in optimisation 3 resulted in the flexors being activated to prevent hyper-extension of the knee. The activation of the knee extensor in optimisation 1 and optimisation 3 remained at the upper level until almost the end of the simulations. In contrast to this, in the robust optimisation 4 the activation level of the knee extensor started to drop off fairly rapidly after about $100 \mathrm{~ms}$ (Figure 4c). Although optimisation 3 did not violate any of the anatomical constraints it was close to doing so as shown by the perturbation effects in Table 3. Optimisation 4 overcame this problem at the knee by reducing the knee angular velocity to almost zero at takeoff (Table 3). The de-activation of the knee extensors in optimisation 4 helped to prevent the knee from hyper-extending. This de-activation of the knee extensors plays an important role in the generation of a simulation that is robust to small perturbations in torque generator activation timings in terms of both peak height and anatomical limits. While it has been recognised that such anatomical constraints may have an effect on performance (van Soest et al., 1993), the inclusion of such considerations in 
simulation studies has been typically confined to incorporating passive spring systems for restricting joint movement (e.g Ashby and Delp, 2006). In this study no such passive constraints were used since compliance with anatomical constraints is normally effected by the neuromusculoskeletal system employing appropriate activation timing and since passive structures typically sustain injury when they are required to produce large torques.

The optimisation of human movement using modelling procedures has been largely confined within mechanical constraints whereas optimisation in biological systems takes place under wider considerations (Newell, 1985). Humans adopt a process of self-optimisation to find a stable and realistic solution within a context of constraints and perturbations. The imposed constraints are those associated with the activity, those which are dependent on the structure of the system and those which are associated with environmental conditions (Newell, 1986). Since the human system must work within such constraints when learning any task it is likely that the evolution of coordination patterns has incorporated these requirements. As a consequence the influence of constraints may have as much relevance to sub-maximal movements as to maximal performance.

\section{References}

Alexander, R. McN., 1990. Optimum take-off techniques for high jumps and long jumps. Philosophical Transactions of the Royal Society of London B 329, 310.

Ashby, B.M., Delp, S.L., 2006. Optimal control simulations reveal mechanisms by which arm movement improves standing long jump performance. Journal of Biomechanics 39, 1726-1734.

Bobbert, M.F. and van Zandwijk, J.P., 1999. Sensitivity of vertical jumping performance to changes in muscle stimulation onset times: a simulation study. Biological Cybernetics 81, 101-108.

Brüggemann, G.P., Loch, M., 1992. The high jump. New Studies in Athletics 7, 6772.

Chow, J.W., Hay, J.G., 2005. Computer simulation of the last support phase of the long jump. Medicine and Science in Sports and Exercise 37, 115-123.

Corana, A., Marchesi, M., Martini, C., Ridella, S., 1987. Minimising multimodal functions of continuous variables with the "simulated annealing" algorithm. ACM Transactions on Mathematical Software 13, 262-280.

Dapena, J., Chung, C.S., 1988. Vertical and radial motions of the body during the take-off phase of high jumping. Medicine and Science in Sports and Exercise 20, 290-302.

Dapena, J., 1988. Biomechanical analysis of the Fosbury flop. Track Technique 104, 3307-3317 / 3333-3350.

Dapena, J., McDonald, C., Cappaert, J., 1990. A regression analysis of high jumping technique. International Journal of Sport Biomechanics 6, 246-261.

Greig, M.P., Yeadon, M.R., 2000. The influence of touchdown parameters on the performance of a high jumper. Journal of Applied Biomechanics 16, 367-378.

Harris, C.M., Wolpert, D.M., 1998. Signal-dependent noise determines motor planning. Nature 394, 780-784.

Hubbard, M., Trinkle, J.C., 1985. Optimal Fosbury-flop high jumping. In Winter, D. A., Norman, R .W., Wells, R. P., Hayes, K. C., Patta, A. E. (Eds.). Biomechanics IX-A. Human Kinetics, Champaign. 
Karara, H.M., 1980. Non-metric cameras. In Atkinson, K. B. (Ed.), Developments in close range photogrammetry - 1 (pp. 63-80). Applied Science Publishers, London.

King, M.A., Wilson, C., Yeadon, M.R., 2006. Evaluation of a torque-driven model of jumping for height. Journal of Applied Biomechanics 22, 264-274.

Newell, K.M., 1985. Coordination, control and skill. In Goodman, D., Wilberg, R.B., Franks, I.M. (Eds.). Differing perspectives in motor learning, memory and control. Elsevier Science Publishers B.V., North-Holland.

Newell, K.M., 1986. Constraints on the development of coordination. In Wade, M.G., Whiting, H.T.A. (Eds.). Motor development in children: Aspects of coordination and control. Martinus Nijhoff, Dordrecht.

Pandy, M.G., Zajac, F.E., Sim, E., Levine, W.S., 1990. An optimal control model for maximum-height human jumping. Journal of Biomechanics 23, 1185-1198.

van Soest, A.J., Bobbert, M.F., van Ingen Schenau, G.J., 1994. A control strategy for the execution of explosive movements from varying starting positions. Journal of Neurophysiology 71, 1390-1402.

Van Soest, A.J., Schwab, A.L., Bobbert, M.F., van Ingen Schenau, G.J., 1993. The influence and biarticularity of the gastrocnemius muscle on vertical-jumping achievement. Journal of Biomechanics 26, 1-8.

Umberger, B.R., 2005. Constraints necessary to produce realistic simulations of countermovement vertical jumping, and the effects on achieved jump height. In Proceedings of the 2005 International Symposium on Computer Simulation in Biomechanics, pp. 35-36. Case Western Reserve University, Cleveland.

Wilson, C., Yeadon, M.R., King, M.A., 2006. Determination of subject-specific model parameters for visco-elastic elements. Journal of Biomechanics 39, 1883-1890.

Wood, G.A., Jennings, L.S., 1979. On the use of spline functions for data smoothing. Journal of Biomechanics 12, 447-479.

Yeadon, M.R., 1990a. The simulation of aerial movement - I: The determination of orientation angles from film data. Journal of Biomechanics 23, 59-66.

Yeadon, M.R., 1990b. The simulation of aerial movement - II: A mathematical inertia model of the human body. Journal of Biomechanics 23, 67-74.

Yeadon, M.R., 1990c. The simulation of aerial movement - III: The determination of the angular momentum of the human body. Journal of Biomechanics 23, 7583.

Yeadon, M.R., King, M.A., 1999. A method for synchronising digitised video data. Journal of Biomechanics 32, 983-986.

Yeadon, M.R., Wilson, C., King, M.A., 2006. Modelling differential activation of knee joint extensors. Journal of Biomechanics 39, 476-482. 